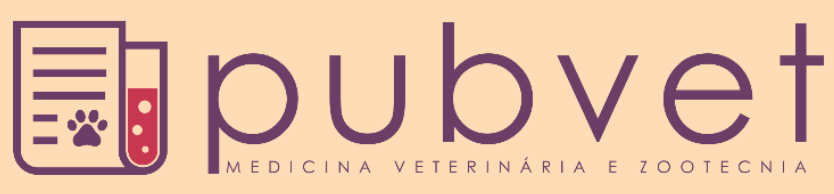

https://doi.org/10.31533/pubvet.v16n02a1039.1-8

\title{
Crescimento animal e critérios de abate em ovinos
}

\author{
Mariana Dalla Favera Almeida de Oliveira ${ }^{1 *} \bullet$, Sergio Carvalho ${ }^{2 *}$, Viviana Reboledo da \\ $\operatorname{Costa}^{1 \circledast}$, Bernardo da Trindade Gallarreta ${ }^{1 \oplus}$, Daniel Uliana ${ }^{3 \circledast}$, Diúlia Zolin Galvani ${ }^{1 \oplus}$, Larissa \\ Lopes Barbosa $^{4 \circledast}$, Pedro Henrique Galvão ${ }^{3 \circledast}$, Elen Kaline Sartori ${ }^{3 \oplus}$, Mateus Alcimar Farias ${ }^{3 \circledast}$
}

\footnotetext{
${ }^{1}$ Aluno(a) da Universidade Federal de Santa Maria, Programa de Pós-graduação em Zootecnia. Santa Maria - RS, Brasil. ${ }^{2}$ Professor da Universidade Federal de Santa Maria, Departamento de Zootecnia. Santa Maria - RS Brasil.

${ }^{3}$ Aluno(a) da Universidade Federal de Santa Maria, curso de graduação em Zootecnia. Santa Maria - RS Brasil.

${ }^{4}$ Zootecnista graduada pela Universidade Federal de Santa Maria. Santa Maria - RS, Brasil.

*Autor para correspondência, E-mail: marianadallaf@gmail.com
}

Resumo. O estado nutricional da carne, depende além da alimentação, da genética, sexo e idade do animal. Os diferentes tecidos que compõem a carcaça dos animais apresentam diferentes velocidades de crescimento, sendo o tecido ósseo mais precoce, o muscular com crescimento intermediário e a gordura depositada mais tardiamente. Há muitos estudos sobre as características relacionadas com a qualidade de carcaça, porém são poucos os que abordam a qualidade da carne e os fatores que influenciam no produto final. Para isso, é preciso definir o momento ideal de abate, visando obter a carne com as melhores proporções de músculo e gordura. A definição do momento de abate é feita através de alguns critérios, podendo ser desde a idade, peso corporal, estágio de maturidade até a condição corporal. Com isso, objetivo desse estudo foi realizar uma revisão de literatura sobre o crescimento e desenvolvimento animal e os critérios utilizados para definir o momento de abate de ovinos. Os critérios utilizados são a morfologia e conformação, a época, idade, peso corporal, o sexo, o estágio de maturidade tecidual e química e a condição corporal. Entender o crescimento e o desenvolvimento animal é de suma importância para uma produção eficiente, pois identificando como ocorre o crescimento dos tecidos da carcaça podemos determinar o momento mais adequado para abater cada grupo de animais, obtendo uma padronização e maior qualidade dos produtos. Diante do exposto, estabelecer critérios para definir o momento adequado de abate em ovinos é importante para que esses animais apresentem nesse momento uma adequada relação músculo:gordura na carcaça bem como uma eficiência alimentar que não venha a comprometer o desempenho produtivo e econômico da atividade. Animais mais jovens apresentam uma quantidade maior de músculo e menos gordura do que animais mais maduros. Para obtermos melhor eficiência na produção, devemos associar dois ou mais critérios, como por exemplo a idade e a condição corporal, assim podemos definir se o animal está pronto para o abate.

Palavras chave: Abate, crescimento, desenvolvimento tecidual

\section{Animal growth and slaughter criteria in sheep}

Abstract. The nutritional status of meat depends in addition to food, genetics, sex and age of the animal. The different tissues that compose the carcass of the animals have different growth rates, with bone tissue being earlier, muscle tissue with intermediate growth and fat deposited later. There are many studies on characteristics related to carcass quality, but few address meat quality and the factors that influence the final product. For this, it's necessary to define the ideal time for slaughter, aiming to obtain the meat with the best proportions of muscle and fat. The definition of the slaughter time is made through some criteria, which can be defined from age, body weight or maturity stage to body condition. Also, the purpose of this study was to conduct a literature review on animal growth and development and the 
criteria used to define the time of slaughter of sheep. The criteria used are morphology and conformation, time, age, body weight, sex, tissue and chemical maturity stage and body condition. Understanding animal growth and development is of paramount importance for efficient production, as by identifying how the carcass tissue grows, we can determine the most appropriate time to slaughter each group of animals, achieving standardization and higher quality of products. Given the above, establishing criteria to define the appropriate time for slaughter in sheep is important for these animals to present an adequate muscle:fat ratio in the carcass at that time, as well as feed efficiency that does not compromise the productive and economic performance of the activity. Younger animals have more muscle and less fat than older animals. To obtain better efficiency in production, we must associate two or more criteria, such as age and body condition, so we can better define the proportion of muscle and fat in the animal, that is, define whether the animal is ready for slaughter.

Keywords: Growth, slaughter, sheep

\section{Introdução}

Segundo dados do IBGE (2020), o rebanho gaúcho de ovinos possuía mais de 2.950 mil cabeças de animais, representando aproximadamente $14 \%$ do rebanho nacional. Segundo a Associação Brasileira de Criadores de Ovinos, o consumo de carne ovina no Brasil era de 400g por pessoa em 2018. No entanto, nos últimos anos tem-se observado uma maior procura dos consumidores pela carne ovina, principalmente a carne de cordeiro, a qual é uma excelente fonte de proteínas e aminoácidos, possui baixa quantidade de lipídeos e gorduras saturadas. Além das propriedades nutricionais, a carne de cordeiro também é valorizada por suas características sensoriais, como o aroma, maciez, sabor e por sua consistência (Sainz, 2000; Sañudo \& Sierra, 1986).

O mercado consumidor define como carne de qualidade, uma carne que possua uma quantidade alta de tecido muscular, pouco tecido ósseo e adequada deposição de gordura. A carne ovina se enquadra nessas necessidades, mas para isso é fundamental saber o momento exato de abate dos animais (Alves et al., 2014; Azeredo et al., 2014; Osório et al., 2002). Produzir uma carne de qualidade não é uma tarefa fácil, é preciso conhecer cada fator que possa interferir no produto final. $\mathrm{O}$ estado nutricional da carne depende, além da alimentação, da genética, sexo e idade do animal (Rotta et al., 2009). Portanto é importante levar em conta esses fatores no momento de abater os animais, visando a maior qualidade de acordo com o que o consumidor procura. Ocorre que os diferentes tecidos que compõem a carcaça dos animais apresentam diferentes velocidades de crescimento, sendo o tecido ósseo mais precoce, o muscular com crescimento intermediário e a gordura depositada mais tardiamente.

Há muitos estudos sobre as características relacionadas com a qualidade de carcaça, porém são poucos os que abordam a qualidade da carne e os fatores que influenciam no produto final (Jardim et al., 2007; Osório et al., 2014; Roque et al., 1999). Para isso, é preciso definir o momento ideal de abate, visando obter a carne com as melhores proporções de músculo e gordura. A definição do momento de abate é feita através de alguns critérios, podendo ser desde a idade, peso corporal, estágio de maturidade até a condição corporal. Com isso, objetivou-se realizar uma revisão de literatura sobre o crescimento e desenvolvimento animal e os critérios utilizados para definir o momento ideal de abate dos ovinos.

\section{Crescimento e desenvolvimento ovino}

Entender o crescimento e o desenvolvimento animal é de suma importância para uma produção eficiente, pois conhecendo os processos envolvidos no crescimento dos tecidos da carcaça podemos determinar o momento mais adequado para abater cada grupo de animais, obtendo uma padronização e maior qualidade dos produtos (Hashimoto et al., 2012). Para Osório et al. (2014), o estudo das curvas de crescimento permite melhorar a eficiência da produção animal, podendo-se associar fatores intrínsecos e extrínsecos para indicar o momento ideal de abate. Os mesmos autores ainda explicam que, crescimento além de ser a multiplicação de células, também é o aumento de tamanho, o que chamamos de hiperplasia e hipertrofia (Osório et al., 2014). Para Gois et al. (2018), o crescimento se define pelo aumento no número e volume das células, sendo indicado pelo incremento do peso corporal do animal. Já o desenvolvimento é conceituado pelo aumento de volume das células ao ponto de permitir que os órgãos e tecidos exerçam suas funções. O crescimento e o desenvolvimento de um animal iniciam no 
momento de sua concepção, sendo os nutrientes utilizados em função da ordem de desenvolvimento dos órgãos.

É importante salientar que a curva de crescimento dos tecidos tem características alométricas, onde cada tecido tem crescimentos diferentes entre si. Pode-se observar que os músculos têm maior crescimento em animais mais jovens, já a gordura tem seu crescimento acentuado em animais mais velhos e os ossos têm uma curva de crescimento menos acelerada quando comparada aos demais tecidos. A curva de crescimento é sigmoide, ou seja, nos animais mais jovens o crescimento é rápido e fica mais lento com a aproximação da puberdade, diminuindo gradativamente até a fase adulta (Gois et al., 2018). Ao avaliar a composição regional e tecidual da carcaça, Alves et al. (2015) destacam que "a deposição dos tecidos segue uma ordem gradativa: osso, músculo, gordura visceral, gordura intermuscular, gordura subcutânea e a gordura intramuscular (marmoreio)". Nesse contexto, de uma forma geral, à medida que a idade e/ou o peso de abate aumentam, normalmente ocorre a produção de carcaças mais gordurosas e com diminuição da relação músculo/gordura, o que vai contra a atual demanda do consumidor de carne ovina.

Outro fator importante a ser destacado é que a eficiência alimentar decresce com o avançar da idade dos animais. Isso ocorre devido ao aumento dos requerimentos de mantença, e do aumento do gasto energético para a deposição de tecido adiposo em detrimento a do tecido muscular. Sabe-se que o tecido adiposo apresenta aproximadamente $10 \%$ de água e tem um gasto energético de $8,3 \mathrm{kcal} / \mathrm{g}$ de tecido, enquanto que o tecido muscular apresenta $78 \%$ de água e gasto energético de $1,2 \mathrm{kcal} / \mathrm{g}$ de tecido. Essa afirmativa pode ser embasada por Venturini et al. (2016), os quais comparando diferentes categorias ovinas terminadas em sistema de confinamento, observaram maior ganho de peso e melhor eficiência alimentar para a categoria dos cordeiros quando comparados a categoria dos borregos.

\section{Critérios para o abate de ovinos}

\section{Morfologia e conformação}

O objetivo de classificar as carcaças de acordo com a morfologia e conformação é criar um padrão animal para o mercado, proporcionando diferentes categorias com características semelhantes ao que o consumidor final procura. Muitos países empregam o critério de conformação como sistema de avaliação de carcaças devido às expectativas em mais cortes de qualidade, maior espessura dos músculos e carcaças conformadas.

Os principais componentes da carcaça são o osso, músculo e gordura, os quais dependem, segundo Osório et al. (2012), da massa de cada componente do conjunto, da forma de cada componente para a mesma massa e da posição que ocupa. Esses fatores irão alterar a forma como o observador visualiza a conformação animal. Os autores destacam que uma carcaça com boa conformação é aquela que tem dominância de perfis convexos e de diâmetros transversais em relação a perfis côncavos e diâmetros longitudinais, ou seja, as carcaças "com forma curta, larga, redonda e compacta" tem melhor conformação.

Silva et al. (2009) explicam que a conformação expressa o desenvolvimento muscular e é obtida por meio da verificação dos perfis musculares. Para a determinação do grau de conformação são informados índices de um a cinco, com variação de 0,5 , onde (1 - Inferior; 2 - Regular; 3 - Boa; 4 - Muito boa e 5 - Excelente). A seleção de animais pela conformação resulta em melhor rendimento de carcaça e maior quantidade de produto, porém tem-se demonstrado que uma boa forma por si, é alcançada em função do excesso de gordura, a qual apresenta grande influência sobre a forma (conformação), a gordura subcutânea principalmente, devido sua influência alterar as aparências exteriores do animal, graças a sua localização imediatamente embaixo da pele, a gordura intermuscular pelo sutil deslocamento da musculatura.

Sendo assim, nessa situação, com aumento da gordura, a conformação melhora e a porção comestível (razão músculo:gordura) pode não ser a desejada pelo consumidor, uma vez que o excesso de gordura é indesejado (Osório et al., 2012). Além disso, conforme comentado anteriormente, para produzir gordura é necessário mais quilo calorias do que para produzir músculo. Logo, não é interessante para o produtor. Portanto, se o animal apresentar melhor conformação no momento do abate melhor. Contudo, morfologia e conformação não devem ser utilizadas como critério único de abate em ovinos. 


\section{Época, idade e peso corporal}

A época, idade e o peso corporal têm grande importância na produção e qualidade da carne. O peso corporal aumenta com a idade, e em sistemas extensivos varia de acordo com a época. Essa variação ocorre devido a disponibilidade dos alimentos, escassos em determinadas épocas e em outra abundantes em outra, influenciando não só a quantidade, mas também na qualidade desses alimentos e consequentemente nas características da carne. O peso vivo é geralmente utilizado como critério de abate no Brasil, tendo influência sobre as características da carcaça, alterando seus rendimentos e valores (Alves et al., 2020).

Segundo Osório et al. (2014), quando objetiva-se produzir carne, é imprescindível determinar o peso ideal de abate, o que permite uma maior produtividade e irá atender as exigências do consumidor. A época de abate e o peso devem ser adequados com a quantidade de gordura depositada de acordo com o que o consumidor busca. Já a idade de abate, a preferência é por animais mais jovens, sendo eles os cordeiros, em torno dos 90 a 120 dias de idade.

Quando o animal está atingindo à maturidade, com cerca de $60 \%$ de seu peso adulto, a relação entre músculo e osso aumenta. Já ao passar da idade, a quantidade de músculo é menor e maior proporção de tecido adiposo. Ou seja, quanto maior o peso ao abate, menor relação músculo e osso e consequente maior quantidade de gordura. Deste modo, quando a idade aumenta, a maciez e qualidade da carne diminuem.

Animais muito velhos e com elevado teor de gordura geralmente não são desejados pelo público consumidor, tendo-se que com o aumento da idade e do peso corporal ocorre também o aumento da deposição de gordura. Ao avaliar o rendimento e qualidade de carcaça a partir dos componentes teciduais de cordeiros abatidos em diferentes idades, Osório et al. (2014) concluíram que animais abatidos aos 90 dias de idade demonstraram maior proporção de músculo, já os abatidos aos 180 dias maior percentual de gordura nos cortes analisados. Segundo o autor, quanto mais maduros os animais, maior será a quantidade de gordura na carcaça, já nos tecidos muscular e ósseo não se observa esse crescimento de acordo com a idade.

Pinheiro et al. (2007) ao avaliarem a composição tecidual em osso, músculo e gordura dos cortes de carcaça em animais jovens e adultos encontraram resultados com menor percentual de ossos em animais mais velhos do que em cordeiros, devido os mesmos apresentarem maior quantidade de gordura total. A razão músculo:gordura também foi melhor para a categoria mais jovem. Em um estudo realizado por Azeredo et al. (2014), foi observado que ovinos abatidos com 120 dias de idade apresentaram carcaças melhores conformadas, mesmo tendo apresentado menores pesos corporais em relação a animais abatidos mais tarde, com 210 e 360 dias de idade. Jardim et al. (2007) observaram porcentagens superiores de gordura intermuscular e subcutânea nos cortes paleta e perna para ovinos abatidos aos 120 dias, comparados aos abatidos aos 210 e 360 dias. O autor também encontrou alto teor de proteína na carne dos animais de 120 dias, que ocorre devido aos músculos ainda estarem em desenvolvimento. Rosa et al. (2008), ao avaliarem a composição tecidual da carcaça e o crescimento alométrico dos tecidos, observaram que os animais abatidos com $25 \mathrm{~kg}$ tiveram uma menor proporção de gordura e maior de músculo na carcaça do que os animais abatidos com $33 \mathrm{~kg}$. Alves et al. (2020) também observaram um aumento do percentual de gordura de acordo com o aumento do peso corporal. Os animais abatidos com 31 a $45 \mathrm{~kg}$ apresentaram maiores índices de gordura na carcaça. Já a proporção de músculo foi inversa, os animais mais leves, com 16 a $25 \mathrm{~kg}$, tiveram melhor rendimento que os mais pesados.

Ao determinarem a proporção de osso, músculo e gordura na carcaça de ovinos abatidos a diferentes pesos, Silva et al. (2000) observaram diminuição na proporção de osso com o aumento do peso corporal. Os autores concluem que animais abatidos com peso corporal acima de $33 \mathrm{~kg}$ não são adequados. Isso se explica devido as melhores proporções de músculo e gordura encontradas nos animais mais leves.

\section{Sexo}

O critério sexo é dividido entre fêmeas, machos não castrados e machos castrados. O sexo do animal é considerado na identificação de carcaças e na sua comercialização, sendo possível visualizar diferenças no rendimento e na qualidade da carne (Silva et al., 2009). O desenvolvimento dos tecidos também é 
diferente de acordo com o sexo. As fêmeas são consideradas animais mais precoces, os machos castrados são intermediários e os inteiros considerados tardios. A proporção de gordura na carcaça segue essa mesma ordem, o que não acontece com a proporção de músculos que é contrária. Devido as fêmeas depositarem gordura mais cedo, elas devem ser abatidas mais jovens do que os machos inteiros, para que não ocorra um excesso de gordura na carcaça. Em um trabalho realizado por Rosa et al. (2002), os machos tiveram maior potencial de crescimento ósseo e muscular, já as fêmeas, depositaram mais gordura, devido sua precocidade no acabamento da carcaça. Para Azeredo et al. (2005), o peso de abate é menor nas fêmeas e machos castrados quando comparados aos machos inteiros. $\mathrm{O}$ autor explica que a diferença no crescimento entre macho inteiros em relação aos castrados e a fêmea se dá devido a testosterona, a qual estimula o crescimento dos músculos e ossos, presentes nos machos não castrados.

Azeredo et al. (2005) avaliaram o crescimento e desenvolvimento de ovinos da raça Corriedale não castrados, castrados e criptorquidas induzidos, e observaram que aos 210 dias os animais castrados tiveram pesos corporais inferiores aos demais. Esse resultado foi associado ao início da puberdade, que ocorre aproximadamente aos 210 dias.

\section{Estágio de maturidade tecidual e química}

A maturidade é o grau de desenvolvimento dos tecidos do corpo em um peso relacionado a composição do animal ao atingir o peso adulto. Dessa maneira, os animais atingem a maturidade com 40 a $60 \%$ de seu peso adulto (Osório et al., 2012). De acordo com Jardim et al. (2007), a composição química está relacionada com a idade, região corporal e com o tipo e qualidade da alimentação, onde as quantidades de água e proteína reduzem de acordo com a maior idade, resultando em maiores teores de lipídeos. É cada vez maior a atenção dada a esses fatores de qualidade da carne, buscando a satisfação dos consumidores por meio da composição química da carne, sendo mais benéfica nutricionalmente. De acordo com Osório et al. (2014), no momento em que a quantidade de água, proteínas e minerais é constante no corpo do animal, ocorre a maturação química e isso se dá em diferentes idades de acordo com a espécie.

Segundo Silva et al. (2009), "a maturidade da carcaça do ovino pode ser determinada pela observação da estrutura óssea, pela dentição e pela coloração da carne". A classificação pela dentição é feita baseada na quantidade de dentes permanentes que o animal possui, sendo 2, 4, 6 dentes ou boca cheia.

Outro possível indicador da maturação de um animal é a deposição de gordura. Sua quantidade e distribuição afetam o valor da carcaça, sendo o excesso não é desejável pelo consumidor. Os principais depósitos de gordura são: gordura subcutânea (debaixo da pele, gordura intramuscular (marmoreio) e a gordura abdominal (redor do rim e da pélvis). O chamado "acabamento" se visualiza a partir da quantidade e distribuição harmônica da gordura na carcaça, sendo a falta ou excesso de gordura desfavoráveis na produção.

Com a separação dos tecidos da carcaça podemos determinar sua qualidade. O crescimento e desenvolvimentos desses tecidos ocorre na seguinte ordem, osso, músculo, gordura visceral, gordura intermuscular, gordura subcutânea e gordura de marmoreio (Alves et al., 2015). Ao avançar da idade do animal, a deposição de músculo diminui e a deposição de gordura aumenta, levando a uma preferência do consumidor pela carne de animais mais jovens, como a categoria de cordeiros.

\section{Condição corporal}

A condição corporal, segundo Osório et al. (2014), consiste na quantidade de gordura e de outros tecidos presentes no organismo, nos permitindo avaliar o grau de acabamento da carcaça e, por consequência, determinar o momento de abate. $\mathrm{O}$ escore de condição corporal (ECC) é feito por meio da palpação da região lombar ou da inserção da cauda e estima a relação músculo/gordura.

Segundo Osório et al. (2012), a condição corporal estima a razão músculo/gordura, nos possibilitando uma avaliação do estado de engorduramento da carcaça. A gordura de cobertura ou gordura subcutânea possui função protetora, evitando que ocorram perdas e aumentando a maciez da carne. A porção de gordura identificada por meio do escore de condição corporal está relacionada a composição tecidual, qualidade instrumental e sensorial da carne. Utiliza-se uma escala de um a cinco, sendo 1 para um animal extremamente magro e 5 para um animal gordo. 
Da mesma maneira que ocorre no critério maturidade, quando utilizamos o critério condição corporal, identificamos semelhante composição de tecidos na carne, ou seja, semelhante razão de músculo e gordura. Sendo assim, podemos concluir que a condição corporal é um melhor indicador para o momento de abate dos cordeiros, quando comparado com os critérios de peso corporal, idade e conformação.

Por meio da avaliação da condição corporal temos o momento ideal de abate, porém, se associarmos esta informação com outros critérios podemos obter resultados melhores. Osório et al. (2012) quando avaliaram a importância da condição corporal como indicativo da terminação do cordeiro e sua relação com a quantidade de gordura da carcaça, observaram que com o aumento da condição corporal houve maior comprimento e rendimento de carcaça, e também da compacidade corporal. Souza et al. (2011) definiram o escore 3 como ideal para acabamento de carcaça de cordeiros, devido ao animal estar em um grau intermediário, nem magro, nem gordo, fazendo com que se obtenha uma maior eficiência na produção.

Em um estudo realizado por Cartaxo et al. (2008), para avaliar o desempenho animal de cordeiros terminados em confinamento com diferentes condições corporais, os autores observaram influência significativa sobre a conversão alimentar, obtendo-se uma conversão de 3,62 para condição corporal intermediária (escore 2,5 a 3,5) e conversão 4,24 para condição corporal gorda (4,0 a 5,0). Segundo os autores, esses resultados são devido ao maior desenvolvimento de músculos e de gorduras, fazendo com que haja maior formação de gordura e maior consumo de ração. Os animais com condição corporal intermediária tiveram melhor consumo de MS, melhor conversão alimentar e permaneceram menos dias em confinamento o que resultou em menor custo de produção desses animais. Os mesmos autores (Cartaxo et al., 2009), ao avaliarem as características quantitativas de carcaça de cordeiros abatidos com diferentes condições corporais, obtiveram influência da condição corporal nos pesos e rendimentos de carcaça, onde maiores condições corporais resultaram em maiores rendimentos de carcaça. O percentual de gordura interna foi inferior em animais com condição corporal magra (escore de 1,0 a 2,0), pois a maioria dos cordeiros desse grupo apresentavam escore 1,5. Já os cordeiros com condição corporal gorda apresentaram maior espessura de gordura subcutânea quando comparados com as condições inferiores, o que é importante para o acabamento da carcaça. $\mathrm{O}$ índice de musculosidade da perna foi melhor na condição corporal magra, o que permite observar que a partir da condição corporal intermediária não houve crescimento dos tecidos musculares.

\section{Considerações finais}

Para atender a atual demanda do consumidor por uma carne com adequada quantidade de gordura e maciez, a alternativa ideal é abater animais mais jovens, logo que atingem a puberdade. Esses animais apresentam uma quantidade maior de músculo e menos gordura do que animais mais maduros. Devemos também, levar em consideração a raça e o sistema de terminação utilizados.

Para obtermos melhor eficiência na produção, devemos associar dois ou mais critérios, como por exemplo a idade e a condição corporal, assim podemos melhor definir a proporção de músculo e gordura que há no animal, ou seja, definir se o animal está pronto para o abate.

\section{Referências bibliográficas}

Alves, L. G. C., Fernandes, A. R. M., Vargas Júnior, F. M., Cunha, C. M. da, Hirata, A. S. O., Osório, J. C. S., \& Souza, M. R. (2020). Composição e qualidade da carcaça de ovinos com diferentes pesos corporais ao abate. Boletim Da Indústria Animal, 77, 1-14. https://doi.org/10.17523/bia.2020.v77.e1479.

Alves, L. G. C., Osório, J. C. S., Fernandes, A. R. M., Ricardo, H. A., \& Cunha, C. M. (2014). Produção de carne ovina com foco no consumidor. Enciclopédia Biosfera, Centro Científico ConhecerGoiânia, 10(18), 2399-2415.

Alves, L. G. C., Osório, J. C. S., Osório, M. T. M., Fernandes, A. R. M., Ribeiro, E. L. A., da Cunha, C. M., Almeida, H. R., \& Fuzikawa, I. H. S. (2015). Avaliação da composição regional e tecidual da carcaça ovina. PUBVET, 9(1), 6-19. https://doi.org/10.22256/pubvet.v9n1.6-19.

Azeredo, D M, Osório, M. T. M., Osório, J. C. S., Mendonça, G., Barbosa, J., \& Esteves, R. (2005). 
Crescimento e desenvolvimento de ovinos Corriedale não castrados, castrados e criptorquidas abatidos com diferentes pesos. Revosta Brasileira de Agrociências, 11(3), 339-345.

Azeredo, Diego Moreira, Osório, M. T. M., Osório, J. C. S., Mendonça, G., Esteves, R. M., Leon Rota, E., Jardim, R. D., \& Pradiée, J. (2014). Morfologia in vivo e da carcaça e características produtivas e comerciais em ovinos Corriedale não castrados, castrados e criptorquidas abatidos em diferentes idades. Current Agricultural Science and Technology, 12(2).

Cartaxo, F. Q., Cezar, M. F., Sousa, W. H., Gonzaga Neto, S., Pereira Filho, J. M., \& Cunha, M. G. G. (2009). Características quantitativas da carcaça de cordeiros terminados em confinamento e abatidos em diferentes condições corporais. Revista Brasileira de Zootecnia, 38(4), 697-704. https://doi.org/http://dx.doi.org/10.1590/51516-35982009000400016.

Cartaxo, F. Q., Sousa, W. H., Cezar, M. F., Gonzaga Neto, S., \& Cunha, M. G. G. (2008). Efeitos do genótipo e da condição corporal sobre o desempenho de cordeiros terminados em confinamento. Revista Brasileira de Zootecnia, 37(8), 1483-1489. https://doi.org/0.1590/S151635982008000800021.

Gois, G. C., Campos, F. S., Pessoa, R. M. S., Silva, A. A. F., Ferreira, J. M. S., Matias, A. G. S., Sá, G. H. M., Nogueira, M. F., \& Santos, R. N. (2018). Qualidade da carne de ovinos de diferentes pesos e condição sexual. PUBVET, 12, 172.

Hashimoto, J. H., Osório, J. C. S., Osório, M. T. M., Bonacina, M. S., \& Lehmen, R. I. P. (2012). Qualidade de carcaça, desenvolvimento regional e tecidual de cordeiros terminados em três sistemas. Revista Brasileira de Zootecnia, 41(2), 438-448.

IBGE. (2020). Produção da Pecuária Municipal. Disponível em: https://sidra.ibge.gov.br/tabela/3939. Consultado em 30 jun. 2021.

Jardim, R. D., Osório, J. C. S., Osório, M. T. M., Mendonça, G., Del Pino, F. A. B., Oliveira, M. M., \& Prediée, G. (2007). Composição tecidual e quimica da paleta com a perna em ovinos da raça Corriedale. Revista Brasileira de Agrociência, 13(2), 231-236.

Jardim, R. D., Osório, J. C. S., Osório, M. T. M., Mendonça, G., Esteves, R. M. G., \& Gonçalves, M. (2007). Efeito da idade de abate e castração sobre a composição tecidual e química da paleta e da perna de ovinos Corriedale. Current Agricultural Science and Technology, 13(2), 237-242. https://doi.org/10.18539/cast.v13i2.1367.

Osório, J C S, Osório, M. T. M., Fernandes, A. R. M., Vargas Junior, F. M., \& Seno, L. O. (2014). Produção de ovinos no Brasil (Vol. 33). Roca, Brasil.

Osório, J C S, Osório, M. T. M., Oliveira, N. M., \& Siewerdt, L. (2002). Qualidade, morfologia e avaliação de carcaças. In Pelotas: Universidade Federal de Pelotas.

Osório, José Carlos Silveira, Osório, M. T. M., Gonzaga, S. S., da Silva Pedroso, C. E., Esteves, R. G., Ferreira, O. G. L., de Vargas Júnior, F. M., \& Alves, L. G. C. (2012). Terminação de cordeiros. PUBVET, 6(23), Art-1399. https://doi.org/10.22256/pubvet.v6n23.1402.

Pinheiro, R. S. B., Silva Sobrinho, A. G., Yamamoto, S. M., \& Barbosa, J. C. (2007). Tecidual composition of carcass of cuts of young and adult sheep. Pesquisa Agropecuária Brasileira, 42(4), 565-571. https://doi.org/10.1590/s0100-204x2007000400015.

Roque, A. P., Osório, J. C. S. ., Jardim, P. O., Oliveira, N. M., \& Osório, M. T. (1999). Produção de carne em ovinos de cinco genótipos. 6. Desenvolvimento relativo. Ciência Rural, 29(3), 549-553.

Rosa, G. T., Pires, C. C., Silva, J. H. S., Motta, O. S., \& Colomé, L. M. (2008). Composição tecidual da carcaça e de seus cortes e crescimento alométrico do osso, músculo e gordura da carcaça de cordeiros da raça texel. Acta Scientiarum. Animal Sciences, 24(4), 1107-1111.

Rotta, P. P., Prado, R. M., Prado, I. N., Valero, M. V., Visentainer, J. V., \& Silva, R. R. (2009). The effects of genetic groups, nutrition, finishing systems and gender of Brazilian cattle on carcass characteristics and beef composition and appearance: A review. Asian-Australasian Journal of Animal Sciences, 22(12), 1718-1734. https://doi.org/10.5713/ajas.2009.90071.

Sainz, R. D. (2000). Avaliação de carcaças e cortes comerciais de carne caprina e ovina. Simpósio Internacional Sobre Caprinos e Ovinos de Corte, 1(2000), 237-250.

Sañudo, C., \& Sierra, A. I. (1986). Calidad de la canal en la especie ovina. Ovino, 1, 127-153. 
Silva, L. F., Pires, C. C., \& Silva, J. H. S. (2000). Crescimento de cordeiros abatidos com diferentes pesos. 1. Osso, músculo e gordura da carcaça e de seus cortes. Ciência Rural, 30(4), 671-675.

Silva, N. V., Silva, J. H. V., Souza, M. C., Oliveira, E. R. A., Araújo, J. A., \& Lima, A. A. L. (2009). Características de carcaça e carne ovina: uma abordagem das variáveis metodológicas e fatores de influência. Acta Veterinaria Brasilica, 2(4), 103-110.

Souza, K. C., Mexia, A. A., Silva, S. C., Garcia, J., \& Silva Júnior, L. S. (2011). Escore de condição corporal em ovinos visando a sua eficiência reprodutiva e produtiva. PUBVET, 5(1), Art-992. https://doi.org/10.22256/pubvet.v5n1.997.

Venturini, R. S., Carvalho, S., Pires, C. C., Pacheco, P. S., Pellegrin, A., Moro, A. B., Lopes, J. F., Martins, A. A., Bernardes, G. M. C., \& Simões, R. R. (2016). Consumo e desempenho de cordeiros e borregos alimentados com dietas de alto concentrado de milho ou sorgo. Arquivo Brasileiro de Medicina Veterinária e Zootecnia, 68, 1638-1646. https://doi.org/10.1590/1678-4162-8856.

Histórico do artigo:

Recebido: 1 de outubro de 2021

Aprovado: 13 de novembro de 2021

Disponível online: 24 de fevereiro de 2022
Licenciamento: Este artigo é publicado na modalidade Acesso Aberto sob a licença Creative Commons Atribuição 4.0 (CC-BY 4.0), a qual permite uso irrestrito, distribuição, reprodução em qualquer meio, desde que $o$ autor e a fonte sejam devidamente creditados. 